\title{
FREIGHT FORECASTING ALONG NORTH SOUTH ECONOMIC CORRIDOR BASED ON FUZZY LINEAR REGRESSION
}

\author{
Yuanchun Xia ${ }^{a}$, Boonsub Panichakarn ${ }^{\mathrm{b}}$, Sahas Bunditkulc

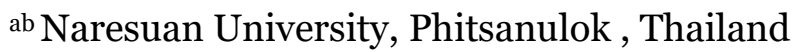 \\ c Asian Institute of Technology, Bangkok, Thailand \\ Corresponding email: 303492135@qq.com
}

\begin{abstract}
This paper aims to make a prediction of freight volume along NSEC (North South Economic Corridor) in a quantitative approach. To start, a brief introduction to NSEC is presented, in which the reason why the prediction is critical important in this field of research is explained and the basic three notions for this research are indicated. Afterwards, parameters of the freight volume is analyzed through GRA (Grey Analysis ), then the model is to be set up for forecasting based on data in the past ten years (2005 to 2015). The following sections are the testing of the model for adjustment of the data and the mode as well. Thereafter, the forecasting of freight volume is concluded after the predication of parameters. Some limitations and recommendations are also presented for further study at the ending section.
\end{abstract}

Keywords: NSEC (North South Economic Corridor), GRA (Grey Analysis), FLR (Fuzzy Liner Regression), Freight Forecasting.

\section{Introduction and Purpose}

North South Economic Corridor (NSEC), as one of the nine corridors ${ }^{1}$ in $\mathrm{GMS}^{2}$, remains to be the flagship project under economic cooperation program of ADB (Asia Development Bank) in terms of demographic situation, traffic volume, connectivity, processing, markets and export nodes. Along this corridor, the current traffic volume is likely the highest considering its endpoint, Bangkok, Thailand, although in northern section, part ofthe exports might divert toHai Phong, Viet Nam. In addition, the connectivity could be demonstrated by 5 airports along the route ( 5 are international airports), proximity to railroad 3 and access to sea ports4.Further, large concentration of Economic Zones (EZ's) around Bangkok(The United

\footnotetext{
${ }^{1}$ Currently, nine corridors in the GMS are: 1)North-South Corridor: Kunming to Bangkok; 2) Eastern Corridor: Kunming to Ca Mau; 3) East-West Corridor:Mawlamyine to Da Nang; 4) Southern Corridor: Dawei to QuyNhon/Vung Tau; 5) Southern Coastal Corridor: Bangkok to Nam Can; 6) Central Corridor: Kunming to Sihanoukville/Sattahip; 7) Northern Corridor: Fangcheng to Tamu; 8)Western Corridor: Tamu to Mawlamyine; 9) North eastern Corridor: Thanh Hoa to Bangkok/Laem Chabang.

2The Greater Mekong Subregion (GMS) is a natural economic area bound together by the Mekong River, covering 2.6 million square kilometers and a combined population of around 326 million( 2013). 3 Largely parallel, from Bangkok to Chiang Mai (Thailand), section planned parallel from Chiang Rai (Thailand) to Menyang (Yunnan Province of PEOPLE'S REPUBIC OF CHINA (PRC)) and again from Mo-Chiang to Kunming (partly under construction).

${ }^{4}$ Bangkok (Thailand): Connection from Tak (Thailand) to Mawlamyine (Myanmar) or Bangkok (Thailand) to Dawei (Myanmar) might reduce time to Europe.
} 


\section{Asia Pacific Journal of Contemporary Education and Communication Technology ISBN (eBook): 9780994365682 । ISSN : 2205-6181 \\ Year: 2017 , Volume: 3, Issue: 2}

Kingdom of Thailand) and Border Economic Zone (BEZ) at border crossings facilitate the import or export of materials or semi-manufactures processed at BEZ or EZ and industrial compositions like electronics, car and car parts, food and food products, chemicals and timber (Lao PDR section) through exports nodes united by Kunming, People's Republic of China (PRC) (airport), Boten and Chiang Kong, Lao PDR (BEZ) as well as Bangkok, Thailand (airport, port).

In this paper, only one route Kunming-Bangkokvia the Lao PDR with two lines in Western Sub-corridor isstudied (See below Chart 1). The one route stretches as below two lines: Kunming-Yuxi -Xishuangbanna-Jinghong -Mohan-Boten, Louang Namthaprovince, Lao PDR-Houaxay, Bokeoprovince, Lao PDR- Chiang Khong, Thailand- ChiangMai - LampangTak- KamphaengPhet-Nakhon Suwan-Ayutthaya-Bangkok. And the other one runs different from Chiang khong in Thailand as Chiang Khong -Phayao- Phrae- Uttaradit-PhitsanulokNakhonSuwan -Ayutthaya-Bangkok.

Chart 1: Three Sections of NSEC

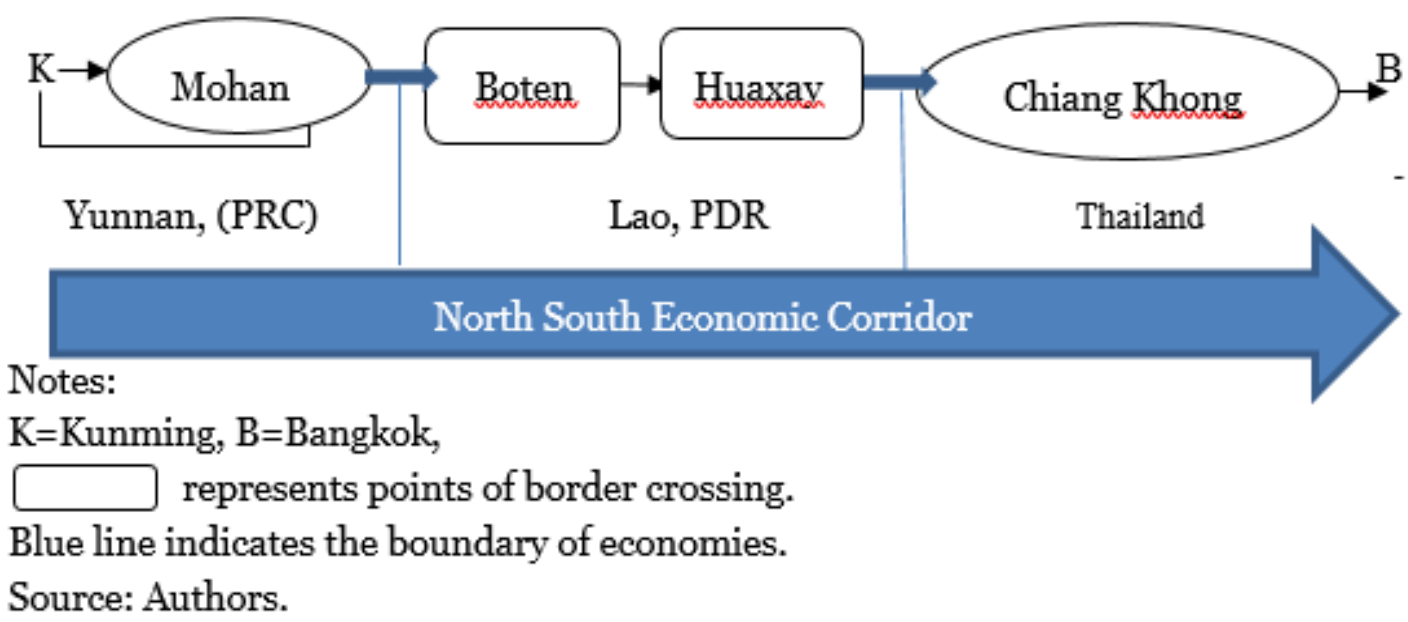

This study is based on the three principal general notions. After its completion, NSEC would entail movement of people and goods along any node, which extends to the areas whose access to major economic centers and the movement could be strengthened through connecting these points as expected or planned. In addition, the study of this corridor is based on the general concept of making full use of the current or existing passage of NSEC, rather than complementing new access or investment into the corridor, which has been witnessed the completion in 2013. In other words, how to utilize this corridor to its utmost potentials, rather than investing complementarily, is one of the underlying purposes for this study. Further, solutions to the current physical connectivity should take the trend of cargo and passengers' volume at present and at future 5 or 10 years into account. So from the chronological aspects, the possible volume in the next 5 years or one or two decades could 


\section{Asia Pacific Journal of Contemporary Education and Communication Technology \\ ISBN (eBook): 9780994365682 | ISSN : 2205-6181 \\ Year: 2017, Volume: 3, Issue: 2}

influence the regulations, cooperative strategies among members along this corridor and countermeasures for the obstacles quo. The existing researches, however, from the perspectives of impact analysis in both positive and negative way, do not discuss how many freight or passengers could be expected after completion of this NSEC, or what is the difference between the real existing volume of cargo or passengers and the expected ones, which are what the policy makers of transportation planning should rely upon.

In addition, transportation planning plays an important role in a macro-level management system in every country, since its economic, social, cultural and political effects are quite obvious. In an efficient transportation network, all available modes are expected to operate consistently to decrease the traffic congestion on roadways. However, without using roadway networks, connecting all nodes is very expensive and to some extent impossible in practice. Therefore, the approximate estimation of road freight transportation (RFT) based on the current volume between various nodes is specifically remarkable in macro-level planning, which is particular the case in cross-border corridor with more than one members along NSEC.

This paper aims to make a prediction of freight volume along NSEC in a quantitative approach. Through Grey Analysis, setting-up the model, models testing and adjustment, and the forecasting of each parameter, can be concluded the forecasting of freight volume along NSEC for each calendar year in 2016 to 2015 based on the indicators in 2006 to 2015 . Limitations and recommendation are also presented for further study.

\section{Parameters}

For the forecasting itself, the freight volume of road has close relations with the local economy so that the forecasting of freight volume along NSEC must take determinants or influencing factors into care consideration. From the theoretical way, more determinants will make the model of forecasting more accurate, which, however, would be complex and may go far away from the prediction. Further, too much determinants will result in the incomplete dependence among these determinants, which will lead to the distortion of the forecasting. Thus, it is critical to choose these determinants within manageable scope and with independent correlation.

Thus, some indicators are chosen to estimate the correlation with the road freight volume, such as GDP, POP, infrastructure investment, FDI (Foreign Direct Investment) and trade value. In this research, Grey Correlation (GRA, by Deng Julongin 1980s) 5 is adopted to calculate the correlation of freight volume with each parameters. More details of GRA application for correlation are as followed procedure.

5Grey correlation analysis can quantitatively explain the uncertain relative situation during objects or the relative situation of system factors and main action which changes with time. It analyzes and confirms the influence degre e of factors according to the geometry approach degree of behavior actor list and data list, that is to say, it compar es them according to the similar degree of data list geometric relation and curves geometric shape, so takes the si milar degree of curves as the weigh yardstick of correlation degree. 


\section{Asia Pacific Journal of Contemporary Education and Communication Technology \\ ISBN (eBook): 9780994365682 । ISSN : 2205-6181 \\ Year: 2017 , Volume: 3, Issue: 2}

A P I A R

Firstly, taking the initial value of road freight volume (m group) and 5 Parameters as a dimension; set

$$
\begin{aligned}
& Y=\left\{\frac{y(1)}{y(1)}, \frac{y(2)}{y(1)}, \ldots \frac{y(i)}{y(1)}, \ldots \frac{y(m)}{y(1)}\right\} \\
& P(j)=\left\{\frac{x(j 1)}{x(j 1)}, \frac{x(j 2)}{x(j 1)}, \ldots \frac{x(j i)}{x(j 1)}, \ldots \frac{x(5 m)}{x(j 1)}\right\} \quad(1 \leq i \leq m, \quad 1 \leq j \leq 5)
\end{aligned}
$$

In above equations, $\mathrm{Y}$ is the first reference sequence of freight volume dimensions; $\mathrm{P}_{\mathrm{j}}$ is the compared dimension of thej ${ }^{\text {th }}$ indicators' dimension ( the first one); $Y_{i}$ represents the actual

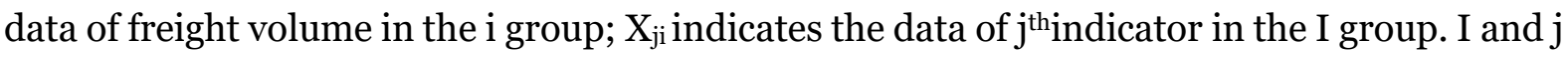
are integers.

Secondly, calculate the difference between the reference sequence and the comparison of sequences, that is,

$$
\begin{aligned}
& \Delta\left(\begin{array}{ll}
\text { j } & \mathrm{i}
\end{array}\right)=|\mathrm{Y}(\mathrm{i})-\mathrm{P}(\mathrm{ji})| \\
& \mathrm{Y}(\mathrm{i})=\frac{\mathrm{y}(\mathrm{i})}{\mathrm{y}(1)} \\
& P(j i)=\frac{x\left(\begin{array}{ll}
j & i
\end{array}\right)}{x\left(\begin{array}{ll}
j & 1
\end{array}\right)}
\end{aligned}
$$

For above equations, $\mathrm{Y}(\mathrm{i})$ is the data in I group of reference sequence; $\mathrm{P}(\mathrm{ji})$ is the value of the $j^{\text {th }}$ indicator in the $i^{\text {th }}$ group in the sequence of comparison; and the $\Delta\left(\begin{array}{ll}j & i\end{array}\right)$ is the difference between the data in I group of reference sequence and the value of the $j^{\text {th }}$ indicator in the $\mathrm{i}^{\text {th }}$ group in the sequence of comparison.

Thirdly, working for the correlation coefficient, that is,

$$
\varepsilon\left(\begin{array}{ll}
j & i
\end{array}\right)=\frac{\Delta \min +\rho \Delta \max }{\Delta(j i)+\rho \Delta \max } \quad(\rho=0.5)
$$

$\rho$ is the recognition differential for avoiding the distortion due to high data of $\Delta \max ; \varepsilon(\mathrm{j} i \mathrm{i})$ is the correlation coefficient between the value of the $j^{\text {th }}$ indicator in the $i^{\text {th }}$ group and the

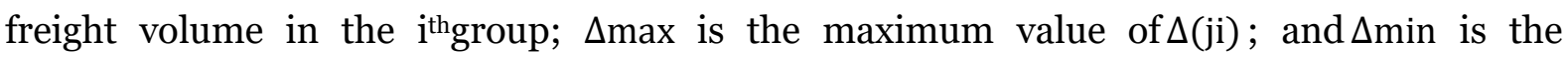
minimum among $\Delta(\mathrm{ji})$.

Lastly, getting the GRA, that is,

$$
\varepsilon(j)=\frac{1}{m} \sum_{i=1}^{m} \varepsilon(j \quad i)
$$

$\varepsilon(\mathrm{j})$ refers to the GRA between the $\mathrm{j}^{\text {th }}$ indicator and the road freight volume $\mathrm{y}$.

\section{Set-up of FLR Model}

\subsection{Parameters}

The FLR model is needed to evolve to the forecasting model for road freight volume. In the classical regression analysis, the deviation between the forecasting value and the actual data is the observation error, which could be deemed as the fuzzy error since the input data and 


\section{Year: 2017 , Volume: 3 , 5 sue: 2}

the output value are obfuscated. Thus, the relation between the road freight volume $y$ and the social indicators is supposed as below

$$
\mathrm{y}=\mathrm{A}_{1} \mathrm{x}_{1}+\mathrm{A}_{2} \mathrm{x}_{2}+\mathrm{A}_{3} \mathrm{x}_{3}+\mathrm{A}_{4} \mathrm{x}_{4}+\mathrm{A}_{5} \mathrm{x}_{5}+\mathrm{A}_{6} \mathrm{x}_{6}+\mathrm{A}_{7} \mathrm{x}_{7}
$$

In this equation, $\mathrm{x}_{1}, \mathrm{x}_{2}, \mathrm{x}_{3}, \mathrm{x}_{4}, \mathrm{x}_{5} \mathrm{x}_{6}$ and $\mathrm{x}_{7}$ represent GDP in Thailand and Yunnan, POP in Thailand and Yunnan, road freight tonnage in Thailand and Yunnan and trade value between Thailand and Yunnan respectively. And $A_{1}$ to $A_{7}$ are the coefficients of counterpart of $x_{1}$ tox $x_{7}$ accordingly.

In the equation (1), the $A_{1}$ should be regarded as the fuzzy coefficient in case of the regression analysis of this equation. Thus, the deviation of forecasting originates from the fuzzy amplitude, which can be demonstrated as a triangular fuzzy number

$\left(A_{j}\left(a_{j}, c_{j}\right)\right)$ with the subordinate function like,

$$
\mu A_{j}=\left\{\begin{array}{l}
1-\frac{|z-a j|}{c j} a_{j}-c_{j} \leq z \leq a_{j}+c_{j} \\
0 \text { others }
\end{array}\right.
$$

For the above equation, $z$ is the precise value of $A_{j}$; $a_{j}$ is the central value of $A_{j}$ and $c_{j}$ is the fuzzy amplitude of $\mathrm{A}_{\mathrm{j}}$.

Therefore, the road volume $\mathrm{y}_{\mathrm{i}}$ in the $\mathrm{i}^{\text {th }}$ group could be witnessed as the following subordinate function as

$$
\begin{gathered}
\mu_{y_{i}}=\left\{\begin{array}{c}
1-\frac{\left|y_{i}-\sum_{j=1}^{7} a_{j} X_{j i}\right|}{\sum_{j=1}^{7} c_{j}\left|X_{i j}\right|} \\
0 \text { others }
\end{array}\right. \\
\left(\sum_{j=1}^{7} a_{j} X_{j i}-\sum_{j=1}^{7} c_{j}\left|X_{i j}\right| \leq \mathrm{y}_{\mathrm{i}} \leq \sum_{j=1}^{7} a_{j} X_{j i}+\sum_{j=1}^{7} c_{j}\left|X_{i j}\right|\right)
\end{gathered}
$$

\subsection{Model Solution}

When analysis is to be taken through the above equation (1), two assumptions should be met. Firstly, for any set of parameters $\left(\mathrm{y}_{\mathrm{i}}, \mathrm{x}_{1 \mathrm{i}}, \mathrm{x}_{2 \mathrm{i}}, \ldots, \mathrm{x}_{\mathrm{ji}}, \ldots \mathrm{x}_{5 \mathrm{i}}\right)$, set a parameter $\mathrm{H}(\mathrm{O} \leq \mathrm{H} \leq 1)$, so,

$$
\mu \mathrm{yi} \geq \mathrm{H}
$$

Secondly, fuzzy coefficient $A_{j}$ has the fuzzy amplitude $D$ as

$$
\mathrm{D}=\sum_{j=1}^{7} c_{j} X_{j i}
$$

So to calculate the minimum $D$ is to get fuzzy coefficient $A_{j}$.

$$
\min \mathrm{D}=\sum_{j=1}^{7} c_{j} X_{j i}
$$

$\sum_{j=1}^{7} a_{j} X_{j i}-(1-\mathrm{H}) \sum_{j=1}^{7} c_{j}\left|X_{i j}\right| \leq \mathrm{y}_{\mathrm{i}}$

\subsection{Goodness of Fit}

Seeking for solutions to the equation (1), a certain standard should be adopted for the goodness of fit of the model through subordinate function $\mu_{y_{i}}$, which represents a good 
degree of fitting in case that the value is bigger than 0.5.

$$
\Phi=\frac{\left|y_{i}-\sum_{j=1}^{7} a_{j} X_{j i}\right|}{y_{i}}(6)
$$

When the $\Phi$ is within the scope of $30 \%$, the goodness of fit is to be acceptable ( $\Phi$ is the ratio between the standard deviation (from the forecasting and actual value of road freight volume) and the actual value.

\subsection{Deviation Analysis}

When the deviation is compared with other methodology of forecasting, this paper adopts mean absolute deviation(MAD), maximum relative error (MMRE)and Mean Relative Error (MRE) for comparison.

Thus, the MAD in the fuzzy linear regression model is

$$
\left|\overline{\mathrm{e}} \mathrm{l}=\frac{1}{\mathrm{~m}} \sum_{i=1}^{m} \quad\right| e_{i}\left|=\frac{1}{\mathrm{~m}} \sum_{i=1}^{m}\right| y_{i}-y_{o i} \mid
$$

$\mathrm{e}_{\mathrm{i}}$ is the absolute deviation in the $\mathrm{i}^{\text {th }}$ group and $y_{o i}$ is the correspondent forecasting value.

And the MRE is to be

$$
\bar{\varepsilon}==\frac{1}{\mathrm{~m}} \sum_{i=1}^{m}\left|\frac{\mathrm{ei}}{y_{i}}\right|=\frac{1}{\mathrm{~m}} \sum_{i=1}^{m}\left|\frac{y_{i}-y_{o i}}{y_{i}}\right|
$$

So, the relative deviation and the MMRE are respectively

$$
\begin{aligned}
& \varepsilon_{\mathrm{i}}=\frac{y_{i}-y_{o i}}{y_{i}}(9) \\
& \varepsilon_{\max }=\max \left(\varepsilon_{\mathrm{i}}\right)
\end{aligned}
$$

\section{Data and Result \\ 4.1 Introduction to Data}

In usual case, the data related with the freight volume in international trade are consisted of GDP, POP, FDI, and trade volume or value and road tonnage. The NSEC, however, are mainly the passage for vegetables and fruits in trade between Thailand and Yunnan (ADB, 2016), thus this predication deletes the parameter FDI, which is less involved in the trade of fruits and vegetables and occupies high percentage of GDP in Thailand case (see Table 1) and thus, is detrimental for the predication result provided that GDP and FDI are the two parameters for forecasting.

Table 1: FDI Inward Percentage of GDP, Thailand and Yunnan

\begin{tabular}{|l|l|l|l|l|l|l|}
\hline & \multicolumn{4}{|l|}{ Thailand } & \multicolumn{3}{l|}{ Yunnan, PRC } \\
\hline Year & GDP & FDI & Percentage & GDP & FDI & Percentage \\
\hline 2001 & 115.54 & 34.75 & 30.08 & 25.83 & 0.65 & 2.52 \\
\hline 2002 & 126.88 & 39.92 & 31.46 & 27.94 & 1.12 & 4.01 \\
\hline 2003 & 142.64 & 51.18 & 35.88 & 30.88 & 1.68 & 5.44 \\
\hline 2004 & 161.34 & 55.15 & 34.18 & 37.24 & 1.42 & 3.81 \\
\hline
\end{tabular}


Year: 2017, Volume: 3, Issue: 2

\begin{tabular}{|l|l|l|l|l|l|l|}
\hline 2005 & 176.35 & 62.83 & 35.63 & 42.26 & 1.74 & 4.12 \\
\hline 2006 & 207.09 & 80.54 & 38.89 & 50.02 & 3.02 & 6.04 \\
\hline 2007 & 246.98 & 96.56 & 39.10 & 62.74 & 3.95 & 6.30 \\
\hline 2008 & 272.58 & 96.64 & 35.46 & 81.92 & 7.77 & 9.56 \\
\hline 2009 & 263.71 & 110.07 & 41.74 & 90.32 & 9.10 & 10.1 \\
\hline 2010 & 318.91 & 142.50 & 44.68 & 106.70 & 13.29 & 12.50 \\
\hline 2011 & 345.67 & 150.52 & 43.54 & 137.63 & 17.38 & 12.63 \\
\hline 2012 & 365.97 & 159.12 & 43.48 & 163.32 & 21.89 & 13.40 \\
\hline 2013 & 400.92 & 185.46 & 46.26 & 184.96 & 25.15 & 13.60 \\
\hline 2014 & 422.29 & & & 198.82 & & \\
\hline 2015 & 413.00 & & & 216.12 & & \\
\hline
\end{tabular}

Notes: GDP and FDI are calculated in billion US\$.

Percentage is indicated by \%.

Source: calculation by authors based on www.tcpdf.org.

Thus, in this paper, the selected parameters for prediction are GDP, POP, road freight tonnage and trade value. Their statistics are shown in Table 2.

Table 2: Statistic Data-1

\begin{tabular}{|l|l|l|l|l|l|l|}
\hline Economies & \multicolumn{4}{|l}{ Thailand } & \multicolumn{4}{l|}{ Yunnan, PRC } \\
\hline Year & GDP & Freight & POP & GDP & Freight & POP \\
\hline 2006 & 207.09 & 427,581 & 63.16 & 50.02 & 606,140 & 44.83 \\
\hline 2007 & 246.98 & 428,123 & 63.32 & 62.74 & 655,370 & 45.14 \\
\hline 2008 & 272.58 & 424,456 & 63.48 & 81.92 & 391,190 & 45.43 \\
\hline 2009 & 263.71 & 423,677 & 63.63 & 90.32 & 407,650 & 45.71 \\
\hline 2010 & 318.91 & 420,449 & 63.79 & 106.70 & 456,650 & 46.02 \\
\hline 2011 & 345.67 & 406,538 & 64.08 & 137.63 & 541,860 & 46.31 \\
\hline 2012 & 365.97 & 425,804 & 64.36 & 163.32 & 632,390 & 46.59 \\
\hline 2013 & 400.92 & 426,086 & 66.75 & 184.96 & 986,750 & 46.87 \\
\hline 2014 & 422.29 & 425,184 & 67.00 & 198.82 & $1,004,234$ & 47.14 \\
\hline 2015 & 413.00 & 426884 & 67.20 & 216.12 & $1,094,950$ & 47.14 \\
\hline
\end{tabular}

Table 2: Statistic Data-2

\begin{tabular}{|c|c|c|}
\hline Year & \begin{tabular}{|l|} 
Thailand-Yunnan's Trade \\
\end{tabular} & Thailand-Yunnan's Volume by Road \\
\hline 2006 & 1.31 & 235,640 \\
\hline 2007 & 2.2 & 230,751 \\
\hline 2008 & 2.5 & 328,088 \\
\hline 2009 & 2.3 & 381,258 \\
\hline 2010 & 4.63 & 619,729 \\
\hline 2011 & 7.4 & 764,060 \\
\hline 2012 & 10.85 & 911,845 \\
\hline 2013 & 10.49 & $1,139,189$ \\
\hline 2014 & 10.73 & $1,531,529$ \\
\hline
\end{tabular}


Notes:

GDP: Gross domestic product (current prices) (Billion US Dollar)

Freight: Road freight tonnage (1000 tones)

POP: Population (Total number of people living in a country / region in millions)

Trade: Thailand - Yunnan trade (current prices) (Hundred Million Us Dollar)

Volume: Cargo volume via Mohan Border Crossing (tones)

Source:

GDP, Freight and POP, GREATER MEKONG SUBREGION STATISTICS on Growth, Connectivity and Sustainable Development, Nay Pyi Taw, Myanmar, 20th Ministerial Conference,10 SEPTEMBER 2015; Thailand-Yunnan Trade, authors collection from the Year Book of Yunnan, 2006-2015; Volume, collection from field visit.

Table 3, from Appendix 1-Correlation Degree Analysis, is the grey correlation of each parameter to the cargo volume. The table indicates that all parameters represent close relation with the cargo volume to the percentage of more than $60 \%$. In particular, the road freight in Thailand has closer correlation to the volume, reaching to 1.57.

Table 3: Correlation Degree

\begin{tabular}{|l|l|l|l|l|l|l|l|}
\hline & \multicolumn{3}{|l|}{ Thailand } & \multicolumn{3}{l|}{ Yunnan } & Yunnan-Thailand \\
\hline Parameters & GDP & Freight & POP & GDP & Freight & POP & Trade \\
\hline Correlation & 0.66 & 1.57 & 0.68 & 0.70 & 0.61 & 0.65 & 0.70 \\
\hline
\end{tabular}

Source: Authors' Calculation.

So, we can select those with more than $70 \%$ of correlation to set up the model as

$$
\mathrm{y}=\mathrm{A}_{2} \mathrm{x}_{2}+\mathrm{A}_{4} \mathrm{x}_{4}+\mathrm{A}_{7} \mathrm{x}_{7}
$$

Then, we take the previous data in year 2006 to 2015 into the model $(\mathrm{H}=0.8)$. With the EXCEL software, the fuzzy coefficients are concluded to be (0.00o,o.0oo), (3168.869,0.00o) and $(58570.933,84602.620)$ respectively. Thus, we can conclude the predictive model asy= $\mathrm{A}_{4} \mathrm{x}_{4}+\mathrm{A}_{7} \mathrm{x}_{7}$

\subsection{Model's Result}

The result is shown in Table 4, with the comparison between the analogue value and true data (volume via Mohan Border Crossing (tones)) in Graph 1.

Table 4: Model Result-1

\begin{tabular}{|l|l|l|l|}
\hline Year & Predicative Volume & True Volume & Deviation \\
\hline 2006 & 235234.7358 & 235640.00 & 0.001719845 \\
\hline 2007 & 327670.8764 & 230751.00 & 0.420019313 \\
\hline 2008 & 406021.0584 & 328088.00 & 0.237537058 \\
\hline 2009 & 420925.369 & 381258.00 & 0.104043375 \\
\hline 2010 & 609301.7128 & 619729.00 & 0.016825559 \\
\hline 2011 & 869556.3071 & 764060.00 & 0.138073328 \\
\hline 2012 & 1153034.264 & 911845.00 & 0.264506867 \\
\hline 2013 & 1200523.047 & 1139189.00 & 0.053840098 \\
\hline
\end{tabular}


Asia Pacific Journal of Contemporary Education and Communication Technology

ISBN (eBook): 9780994365682 I ISSN : 2205-6181

Year: 2017 , Volume: 3, Issue: 2

\begin{tabular}{|l|l|l|l|}
\hline 2014 & 1258500.591 & 1531529.00 & 0.178271785 \\
\hline 2015 & 1673533.259 & 1453000.00 & 0.15177888 \\
\hline
\end{tabular}

Source: Department of Commerce of Yunnan Province,

http://www.bofcom.gov.cn/bofcom/432926140726771712/20160518/398312.html; Ministry of Commerce of People's Republic of China,

http://www.mofcom.gov.cn/article/resume/n/201509/20150901108031.shtml.

Authors' Calculation.

Graph 1: Comparison of Predictive and True Value-1

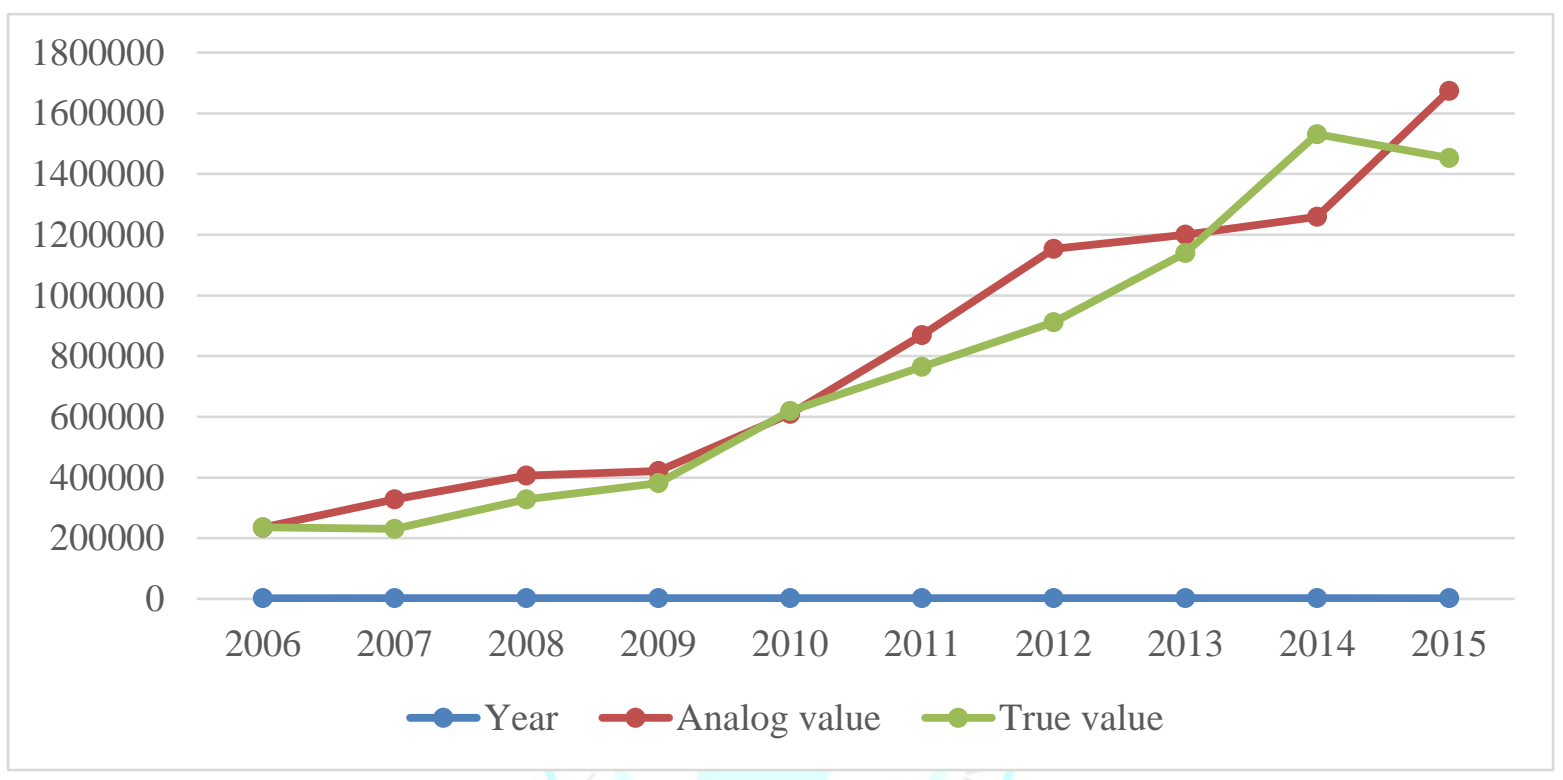

Notes: Volume means cargo volume via Mohan Border Crossing (tones)

Source: Authors' Calculation.

Graph 2: Comparison of Predictive and True Value-2

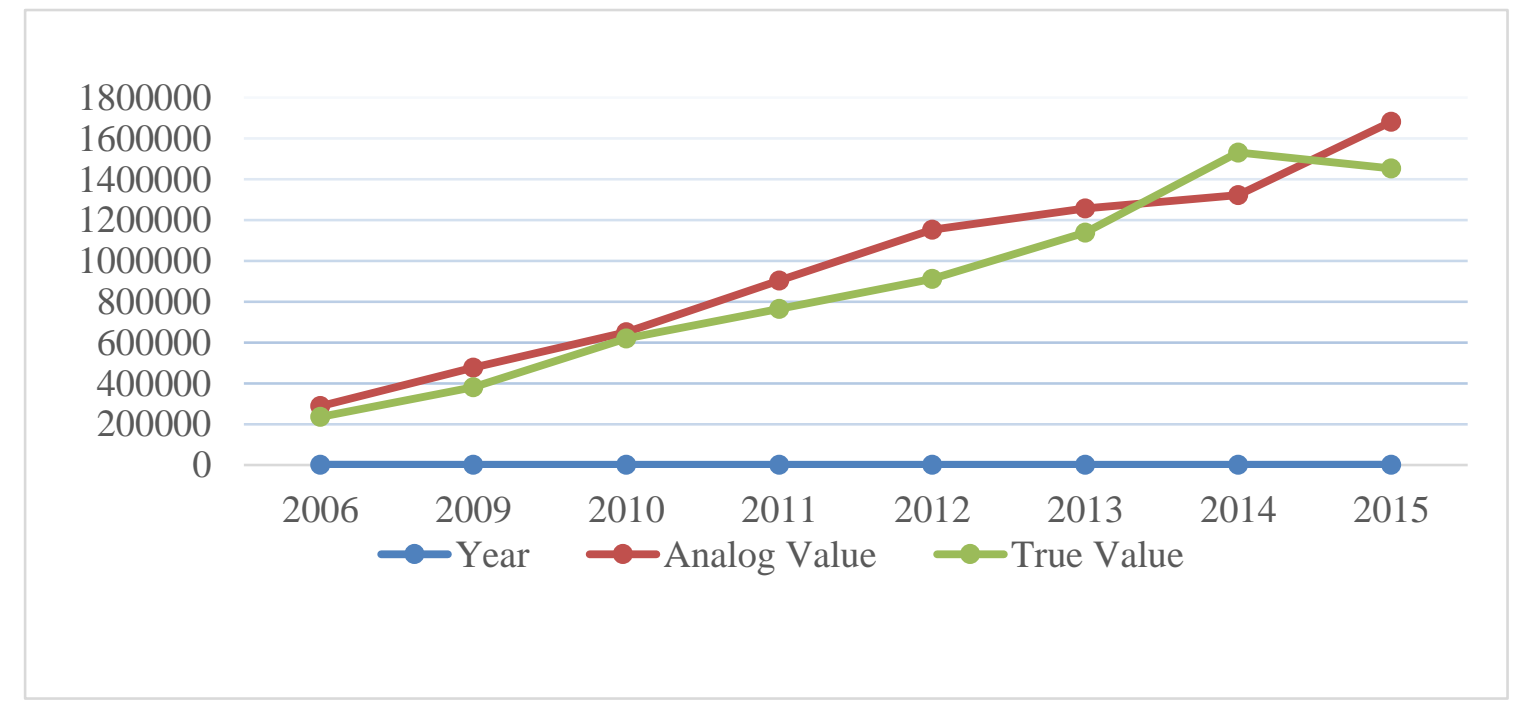

Notes: Volume means cargo volume via Mohan Border Crossing (tones)

Source: Authors' Calculation.

From both above charts, the two maximum deviation occurs in the year of 2007 and 2014, 


\section{Asia Pacific Journal of Contemporary Education and Communication Technology \\ ISBN (eBook): 9780994365682 । ISSN : 2205-6181 \\ Year: 2017 , Volume: 3, Issue: 2}

A P I A R

reaching to about 42 percent and 43 percent, higher than the acceptable benchmark $30 \%$. It is understandable that the year of 2007 witnessed the signs for the financial crisis erupted in 2008, in which economies with certain extent of reliance on the export-orientation would be detrimental and run in abnormal manners since the breakout of the crisis, and the year 2014 is the first year after the completion of NSEC in the end of the 2013. Thus, the data in the year of 2007 and 2014 can be deducted from the result as above two graphs. In addition, with the t-test as 0.148560805 , we can conclude that the model is acceptable for the forecasting.

\section{Predication of Freight}

Therefore, the above model indicates that the fuzzy liner regression model could be adopted for the prediction expected. So, the first step is to estimatethe twoparameters so as to conduct the model for analog value of freight along NSEC.

\subsection{Prediction of Parameters}

In this paper, the predication of GDP in Yunnan and the trade value between Yunnan and Thailand could make access to the predication of freight volume along NSEC. The GDP growth rate in China has been adjust to about $6.7 \%$ by Chinese government. While Yunan's GDP growth rate is a little higher than that of the growth rate in China, so this paper will adopt $7 \%$ growth rate for forecasting of GDP in Yunnan. And 8\% is to be adopted for forecasting the value of trade between Yunnan and Thailand, in accordance with the past data's trend.

Table 5: Forecasting Result of Parameters

\begin{tabular}{|c|c|c|c|c|}
\hline Year & GDP(Yun) & GDP(Prediction) & Trade & Trade ((Prediction) \\
\hline 2006 & 50.02 & & 1.31 & \\
\hline 2007 & 62.74 & 0 & 2.2 & \\
\hline 2008 & 81.92 & 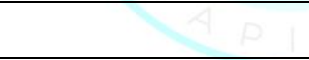 & 2.5 & \\
\hline 2009 & 90.32 & & 2.3 & \\
\hline 2010 & 106.70 & & 4.63 & \\
\hline 2011 & 137.63 & & 7.4 & \\
\hline 2012 & 163.32 & & 10.85 & \\
\hline 2013 & 184.96 & & 10.49 & \\
\hline 2014 & 198.82 & & 10.73 & \\
\hline 2015 & 216.12 & & 16.88 & \\
\hline 2016 & & 231.2484 & & 18.2304 \\
\hline 2017 & & 247.4358 & & 19.688832 \\
\hline 2018 & & 264.7563 & & 21.26393856 \\
\hline 2019 & & 283.2892 & & 22.96505364 \\
\hline 2020 & & 303.1195 & & 24.80225794 \\
\hline 2021 & & 324.3378 & & 26.78643857 \\
\hline 2022 & & 347.0415 & & 28.92935366 \\
\hline 2023 & & 371.3344 & & 31.24370195 \\
\hline 2024 & & 397.3278 & & 33.74319811 \\
\hline
\end{tabular}


Notes:

GDP: Gross domestic product (current prices) (Billion US Dollar)

Trade $=$ Trade between Thailand and Yunnan

Source:

GDP, GREATER MEKONG SUBREGION STATISTICS on Growth, Connectivity and

Sustainable Development, Nay Pyi Taw, Myanmar, 20th Ministerial Conference,10

SEPTEMBER 2015; Thailand-Yunnan Trade, authors collection from the Year Book of Yunnan, 2006-2015. Authors' Calculation.

\subsection{Prediction of Freight Along NSEC}

With the parameters estimate in the future each individual calendar year, the forecasting of freight along NESC could be concluded in Table 5, based on the model set up in equation (3).

Table 6: Forecasting Result in year 2016-2025

\begin{tabular}{|l|l|}
\hline Year & Predicative Volume \\
\hline 2016 & 1800567 \\
\hline 2017 & 1937285 \\
\hline 2018 & 2084427 \\
\hline 2019 & 2242791 \\
\hline 2020 & 2413237 \\
\hline 2021 & 2596691 \\
\hline 2022 & 2794148 \\
\hline 2023 & 3006683 \\
\hline 2024 & 3235450 \\
\hline 2025 & 3481695 \\
\hline
\end{tabular}

Notes: Volume means cargo volume via Mohan Border Crossing (tones)

Source: Authors' Calculation.

From the graphs below, the general trend of the analogue value is indicated. Except the data in the year of 2007 and 2008, the line shows a gradually increasing trend the nearly 2 decades, without too much fluctuation and obvious peak and bottom data. So the liner image from the diagram could be easily demonstrated, with the below chart (Chart $5-1$ ) as a complementary information.

Graph 3: Forecasting Result-Line Graph in year 2016-2025

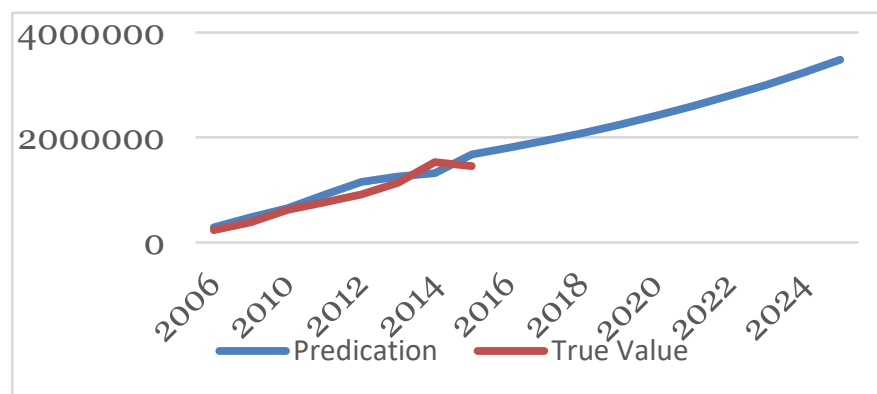

Notes: Volume means cargo volume via Mohan Border Crossing (tones) Source: Authors' Calculation. 


\section{Conclusion}

The general conclusion of this research could be summarized as below. For the freight volume along NSEC, which comes mainly from the trade between Thailand and Yunnan province, PRC, parameters like GDP, POP, Road Freight Tonnage and the trade between Thailand and Yunnan have the close relation with the freight volume, but the correlation degree vary among them and is distinguishing between economies. GDP and POP in both Thailand and Yunnan relates with the freight to the similar level at approximately 64 percent to 69 percent, which indicate that the macroeconomic levels of economies are one of the driving forces of foreign trade, entailing the transnational logistics demand and more freight volume. For the better interdependence of the parameters, FDI is deleted from such variables due to its high correlation with GDP. And road freight tonnage, with the one in Thailand as the most obvious performance, contributes to the freight along this corridor. In particular, the trade between Thailand and Yunnan relates with the cargo to nearly 70 percentages, a good demonstration of the reliance of freight on trade demand. And for the degree of the correlation in terms of the individual economy, Thailand makes the contribution bigger than Yunnan does.

For the freight prediction, the fuzzy liner regression performs well with the deviation within 30 percent, based on data in 2006 to 2015. Considering the financial crisis in 2008, the authors remove the data in 2007 and 2008 for a general testing and adjusting of the model. Afterwards, such predicative parameters are developed into the fuzzy liner regression model and thus, come to the conclusion of the forecasting of freight along NSEC. The total analogue value since 2006 to 2025 shows a gradually climbing up tendency, representing the slope into a liner manner. And the volume in 2025 would be about 1.26 times than the value in 2015 and 12.98 times than it in 2006.

This research, however, exists the following limitations. Firstly, in real practice, the actual freight volume in 2015 is more than 10 times of the one in 2006, a sharp increase in 10 years, in which the year 2014 witnesses the hoist with the biggest ratio. It can be concluded that there are some other factors, quantitative ones in particular, which may occur in the further uncertain years, must influence the freight. Thus, a further research should focus on the qualitative aspects affecting the freight along this corridor such as un-unified regulations, policies in both economic and political, road conditions and maintenance, security situations, officers' proficiency, language barriers and geographical conditions. Secondly, this corridor passes through three economies via border crossings, where some illegal and uncontrollable boundary trade occurs every day, so it is understandable data collection to the utmost accuracy cannot be reached. This is also even the case for customs of three members along this corridor. Therefore, another research is proposed for the control of the illegal trade for a better statistics. Thirdly, the trade value between Thailand and Yunnan province is the key parameters for the forecasting, the freight of this corridor are mainly from the trade, PRC, which may affected by trade complementarities and competitiveness of traded commodities as well as other political and economic factors. So, another separate research to study the bilateral trade in both quantitative and qualitative perspectives are also suggested. And 


\section{Asia Pacific Journal of Contemporary Education and Communication Technology ISBN (eBook): 9780994365682 | ISSN : 2205-6181 \\ Year: 2017, Volume: 3, Issue: 2}

A P I A R

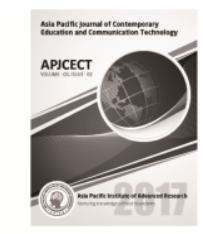

fourthly, the data adopted in this research are mainly referred from Chinese sides, which may differ from the ones supposed they are statistics from Thai and Lao parts. This phenomenon implies that the sharing of the information and unified statistics access among members as well as its security, at least at the cooperative arenas, should be conducted as soon as possible. 


\section{Asia Pacific Journal of Contemporary Education and Communication Technology ISBN (eBook): 9780994365682 | ISSN : 2205-6181 \\ Year: 2017, Volume: 3, Issue: 2}

\section{References}

i. Chen Shi, 2008.The Research of Forecast Method and Application of Cargo. Wuhan University of Technology (M).

ii. Zhao Jian-you, Zhou Sun-feng, Cui Xiao-juan, Wang Gao-qing, Jun, 2012. Predictive method of highway freight volume based on fuzzy linear regression model. Journal of Traffic and Transportation Engineering, Vol. 12. No. 3 . 